\title{
What Do Banks, Rural Credit Institutions, and Regulators Infer from the Current Strengths and Standing of Indonesian SMEs?
}

\author{
Jenri MP Panjaitan ${ }^{* a}$, Mubadjir Darwin ${ }^{a}$ Indra Bastian ${ }^{a}$, and Sukamdi Sukamdi \\ ${ }^{a}$ Universitas Gadjah Mada, Indonesia
}

\begin{abstract}
This study investigates whether the Indonesian regulators control Indonesian small and medium-sized enterprises (SMEs) with matching or mismatching empowerment strategies, in light of their strengths and current standing. Indonesian SMEs contributed approximately $60.34 \%$ to Indonesia's gross domestic product (GDP) in 2018. In addition, Indonesian regulators have focused on financial support through credit policies and tax incentives. Indonesian SMEs have been standing on organizational readiness and readiness for change, based on their social networks and social cognition. It collected thirteen informants with different expertise and experiences. This study's results suggest Indonesia's regulatory body and financial institutions should consider the SMEs' social cognition and organizational readiness for change. According to the current situation, to empower Indonesian SMEs, we recommend strategies such as achieving knowledge supremacy, creating an economic development board, as in Singapore, formulating comprehensive industry-wide policies, adopting omnibus laws, and implementing a shifting balance strategy. In other words, the Indonesian regulators should implement major reforms, which are similar to glasnost and perestroika in the former Soviet Union. This is to enhance Indonesian SMEs and achieve the goal of the Government of Indonesia $(\mathrm{GoI})$ with respect to the optimal distinctiveness of Indonesia's future economy. This optimal distinctiveness refers to the Gol's policies, which focused on knowledge supremacy, an industry-wide regime, and research for empowerment.
\end{abstract}

Keywords: SMEs; social networks; social cognition; organizational readiness for change; strengths; standing; empowerment strategy; governmental policy;

JEL Classification: L16, O31, O43 
Gadjah Mada International Journal of Business - Jan.-April, Vol. 22, No. 1, 2020

\section{Introduction}

Based on the extant literature, an organization ensures its organizational readiness for change regardless of the level of its social networks and social cognition (Boudreaux et al., 2019; Heckmann et al., 2016; Majid and Yasir, 2017; Pruitt, 2015; Walker et al., 2016). Both individual and organizational achievements depend on a high level of commitment, sustainable optimism, and innovativeness(Boudreaux et al., 2019; Majid and Yasir, 2017). This study highlights that most Indonesian SMEs pursue organizational readiness and readiness for change. Additionally, they use social networks and social cognition to empower themselves and enhance their business processes. Therefore, this study investigates whether Indonesian SMEs have achieved an acceptable level, which implies they require new regulations that accommodate this level. Moreover, we examine, in another part of this dissertation, why Indonesian SMEs have overcome their growth sluggishness to become big and mature businesses? Thus, our first research question is as follows: how do Indonesian regulators match their strategies to control and regulate these Indonesian SMEs? In other words, the parallel-first question is: why the regulators and financial institutions did not infer from this SME growth sluggishness the need to develop fresh economic and political directions?

This study offers three unique insights into the development of Indonesian SMEs. First, it evaluates the standing and identifies the strength of Indonesian SMEs, from the perspectives of the social correspondence theory (E. E. Jones and Davis, 1965) and the social comparison theory (Festinger, 1954). Based on these two theories, this article recommends that Indonesian regulators should incorporate the follow- ing guidelines into their policies: achieving knowledge supremacy, reducing the number and influence of agencies that control SMEs, and formulating strategies to achieve an optimal distinctiveness for these SMEs. These policies should be considered and implemented by the Government of Indonesia (GoI) to transform the national economy. Second, this study investigates whether the current regulations can take on the challenges faced by Indonesian SMEs. Moreover, it considers the prospects for these SMEs. Thus, the SMEs' entrepreneurs can develop their future businesses and achieve their goals based on the insights of this paper (Criaco et al., 2017). This study proposes that the match between the strengths and standing of Indonesian SMEs and the current regulations imply their accelerated growth. Furthermore, it argues that this match could enhance the commitment of Indonesian SMEs to supporting national goals. However, a mismatch could reduce the motivation of these SMEs to enlarge and grow their businesses.

Third, this study considers the numerous agencies controlling Indonesian SMEs and the matching and mismatching regulations for SMEs. It then recommends that the GoI should adopt a centralized authorization system and to bundle the currently existing rules into an omnibus law for these SMEs. The centralized authorization system will work as a platform for Indonesian SMEs, which are the basis of the industrial economy (Gawer, 2009; Huntsberger and Greenville, 2008; Rochet and Tirole, 2003). In addition, the bundled regulations will control all the SMEs" activities in an omnibus law, which is similar to the create once, publish everywhere (COPE) technique (Huntsberger and Greenville, 2008; Lin and Daim, 2009; Parker and Van Alstyne, 2014). 
Jenri et al.

However, this study notes that both the industrial economy for SMEs and the omnibus law will not necessarily be achieved if Indonesian regulators do not consider major reforms similar to those under glasnost and perestroika in the former Soviet Union. In other words, Indonesian regulators should promote openness and transparency as well as restructuring the current standing of these SMEs (Gorbachev, 1996; McForan, 1988).

The authors employ the two theories of correspondent inference and social comparison to explain the inference process with respect to the strengths and standing of Indonesian SMEs. The correspondent inference theory explains the behavioral pattern of Indonesian SMEs, as observed systematically in terms of the organizational goals that are to be achieved (E. E. Jones and Davis, 1965). Commerford et al., (2018) suggest that the correspondent inference theory has two stages, which are the observation of patterned and repetitive behavior, and the categorization of this behavior, which goes to form the characteristics and nature of organizations. Moreover, the social comparison theory states that an organization seeks to recognize and evaluate its identity through a comparison with others to reduce uncertainty (Festinger, 1954). Guyer et al., (2018) add that the comparison could include abilities, opinions, feelings, attitudes, physical conditions, achievements, and other personal aspects. Through comparisons, organizations carry out internal evaluations and deal with uncertainty (Aspinwall and Taylor, 1993; Boivie et al., 2015; Criaco et al., 2017; Festinger, 1954; Suls et al., 2002; Wheeler et al., 1997). Both theories are used to analyze and then develop policies for Indonesian regulators, regardless of whether the regulators acknowledge the be- havioral patterns of the Indonesian SMEs.

The remainder of this paper is structured as follows. Section 2 discusses the critical perspective of this study, which elaborates on the two theories (correspondence inference and social comparison). Section 3 presents the research method. Qualitative research was used to search for the conclusion's validities. The lesson learned is presented in Section 4. In this section, the authors explain the loading contents for Indonesian regulators to facilitate, control, and regulate Indonesian SMEs. Section 5 summarizes the study's conclusion, limitations, and implications.

\section{Critical Perspective: Tools For Inferencing}

First, this study employs two theories, namely, the correspondent inference theory and the social comparison theory, to analyze the current strengths and standing of Indonesian SMEs. We use an organizational unit analysis, although these theories use an individual unit analysis. The correspondent inference theory states that behavior patterns can be systematically observed for individual or organizational habits (E. E. Jones and Davis, 1965). This study explains that both people and organizations tend to relate their behavior to unique factors, rather than situational ones. It argues that organizational behavior is formed due to social roles that are derived from familiar routines. (Hamilton et al., 2009) suggest that the correspondent inference theory states that actors choose their steps with respect to them being assigned more stable environmental characteristics. Actors are either individuals or organizations that focus on the underlying disposition of things. Additionally, they focus on establishing their motives and intentions to carry out every social role in their immediate environment. 
Gadjah Mada International Journal of Business - Jan.-April, Vol. 22, No. 1, 2020

Koenig and Eagly (2014) explain that correspondent inference shapes behavioral patterns that are enforced in societal roles. The behavioral patterns in specific roles are then generalized to all group members, to produce stereotypes of the group's characteristics. This study explains that the behavioral patterns of Indonesian SMEs can change because of the dominance of specific regulations or industry groups. Commerford et al., (2018) explain that the correspondent inference theory shows the inferred formation of some dispositions. Individuals or groups first observe certain behaviors, classify these behaviors, and arrange them into a behavioral series with a unique nature and characteristics, producing the continuum points that are further categorized to form the general characteristics that can be observed. Thus, this study clarifies the usefulness of the correspondent inference theory to explain how Indonesian SMEs build internal and external attributes (E. E. Jones and Davis, 1965).

In addition, this theory explains how reputation can influence the manager's opportunities in his/her company. Individual or organizational behavior could be generalized into stereotypes through correspondent inference. Moreover, social roles possessed by organizations create their stereotypes because they have implications for behavioral patterns themselves (Hamilton et al., 2009; Kaplan and Ravenscroft, 2004; Koenig and Eagly, 2014), thus creating their unique characteristics (Commerford et al., 2018). In this study, Indonesian SMEs play the social roles that process the information they observe in their environment. This information has implications for microfinance institutions (MFIs) and regulators, as the actors who manage the results of data. Thus, this study uses the theory of correspondent inference as an analytical tool for the assessment of the implementation of the role of micro, small, and medium-sized enterprises (MSMEs) by MFIs and regulators. The assessment will guide the MFIs and regulators to the formulation of economic and political policies for the development of Indonesian SMEs.

The second critical perspective is the social comparison theory that is used by this study to explain the strategic inference from the strengths and current standing of Indonesian SMEs. Boivie et al., (2015) suggest that social comparisons occur in situations of uncertainty over appropriate behavior. This theory explains that if a person or an organization controls a condition of possibility, they may not necessarily succeed in mastering other challenges that are similar or more difficult (Wheeler et al., 1997), (Suls et al., 2002). However, (Criaco et al., 2017) identified that social comparisons could help individuals evaluate their attitudes and abilities for stability and accuracy. Individuals or organizations tend to choose references to compare their goals, their level of situational involvement, motivation, and information processing capacity. This study employs social comparisons to analyze the entrepreneurial intentions for developing a strong motivation to achieve the SMEs' goals. Similarly, this study explores the process of encouraging Indonesian SMEs to evaluate and deal with environmental uncertainties (Aspinwall and Taylor, 1993; Boivie et al., 2015; Criaco et al., 2017; Festinger, 1954; Suls et al., 2002; Wheeler et al., 1997).

Moreover, this study utilizes logical reasoning based on social comparisons, which are then processed and used to provide insights into the capacities and limitations of either a person or organization (Argo et al., 2006). The existence of social comparisons' cues within an organization triggers the entrepreneurs' intention to develop the SMEs' busi- 
Jenri et al.

ness and focus on achieving their goals (Criaco et al., 2017). Furthermore, this study uses the social comparison theory as an analytical tool to explore the motivation of Indonesian SMEs, and then to analyze the information obtained from their connections with their environment. Thus, the results of the data collected on Indonesian SMEs that have been analyzed could be used as a source for MFIs or regulators to determine the economic and political consequences for them in the future.

\section{Study's Contexts: Strengths And Standing Of Indonesian SMEs}

This study presents the current position of Indonesian SMEs with respect to their social networks, social cognition, organizational readiness, and readiness for change. It takes into account that most Indonesian SMEs have improved their social networks and cognition. In other words, the Indonesian SMEs searched, identified, and internalized social phenomena and problems without neglecting their need for debt and capital (Coleman et al., 2019; Puklavec et al., 2018). Additionally, this study notes that most Indonesian SMEs primarily enhance the dynamic adaptability that requires them to focus on increasing their innovativeness. By considering innovativeness, most Indonesian SMEs have managed to maintain or slightly expand their businesses with their networking and organizational cognition. Finally, this study confirms that most Indonesian SMEs have been developing their organizational powers and improving their business processes dynamically. That is, most Indonesian SMEs have built social networks (Chen et al., 2019; Mehreen et al., 2019; Yamin and Kurt, 2018; Zhou et al., 2007) and enhanced their social learning (Boudreaux et al., 2019; Oo et al., 2018; Wang et al., 2019) due to either improving or enlarging their business operations.

This study considers the strengths of Indonesia's SMEs, which have been enhancing their organizational readiness and readiness for change, indicating that most Indonesian SMEs have established their organizational innovativeness and commitment (Coleman et al., 2019; Puklavec et al., 2018). Additionally, it means that most Indonesian SMEs have always been ready to change, to enhance their innovativeness, commitment, and efficacies (Heckmann et al., 2016; Lizar et al., 2015; Weiner, 2009). This study argues that Indonesian SMEs achieved and maintained their businesses' sustainability and have always searched for new business

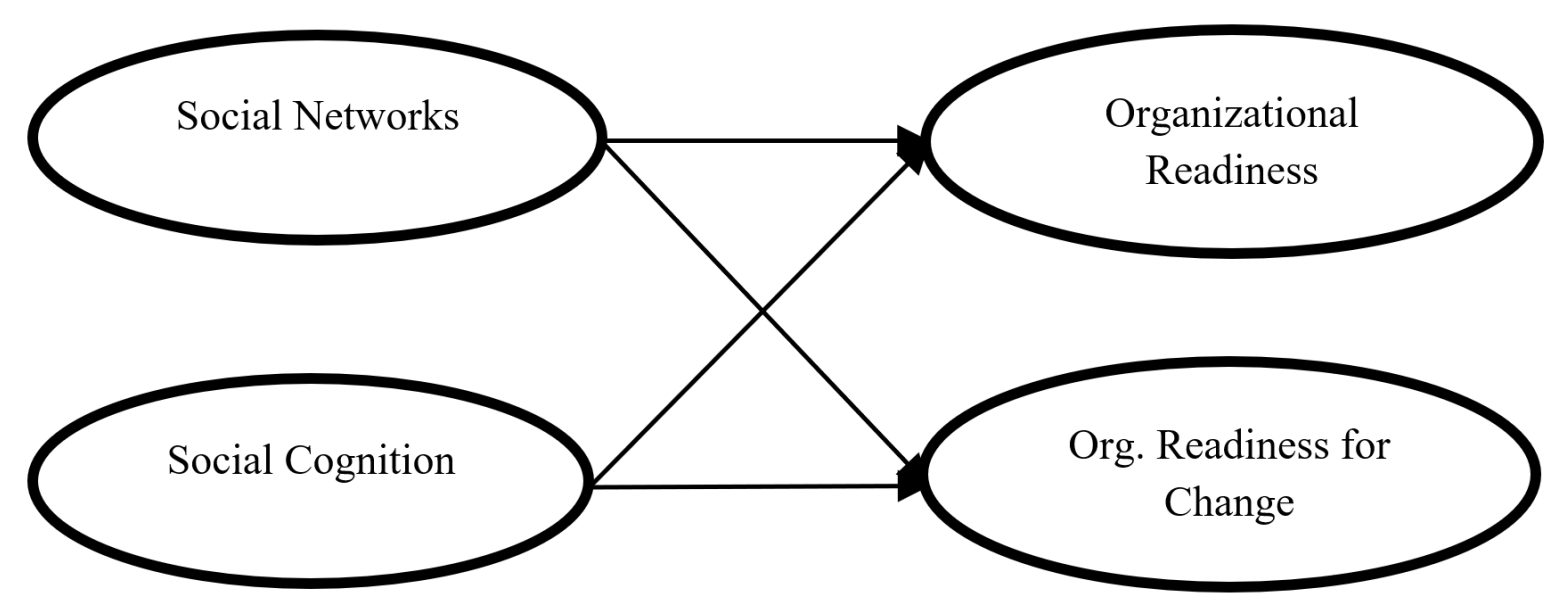

Figure 1. Intuitive-Predictive Model to Investigate SMEs' Organizational Readiness for Change 
Gadjah Mada International Journal of Business - Jan.-April, Vol. 22, No. 1, 2020

opportunities from the perspective of organizational readiness and readiness for change. It, furthermore, argues that business sustainability and innovativeness are these SMEs' strengths, which prepare them for future competition. Finally, we conclude that Indonesian SMEs have built their social networks and social cognition in a profound manner and that most Indonesian SMEs have strengthened their organizational readiness and readiness for change. Consequently, this study develops an intuitive model that explains the strengths and current standing of Indonesian SMEs, as shown in Figure 1. Then this model is investigated using a qualitative research method.

\section{The Research Method}

This study designed its qualitative research method by conducting in-depth interviews.
We picked some key informants who have authority as regulators, decision-makers in financial institutions, and practitioners. We select informants purposively from three different expertise domains: regulators, practitioners, and academicians. Based on informants with these three knowledge types, this study can gather comprehensive information that could be used to interpret the behavioral patterns of Indonesian SMEs. This study, therefore, infers the behavioral patterns of political and economic policies by the Indonesian regulators. Table 1 shows the selected informants who participated in this study.

We conduct our in-depth interviews using the following standard procedures. The in-depth interviews adhere to the saturation principle, which occurs when any further data collection is no longer needed; that is, the existing information reaches a saturation

Table 1. Informants for this Study

\begin{tabular}{|c|c|c|c|c|c|}
\hline No. & Name & Current Occupation & Working Experience & Sector & Code \\
\hline \multirow[t]{4}{*}{1} & \multirow[t]{4}{*}{ Fahmi Akbar Idries } & President Director; & Board of Commisioners: & CEO - Cooperation; & IF-01 \\
\hline & & \multirow{3}{*}{$\begin{array}{l}\text { Parent Cooperation of } \\
\text { Syirkah Muawwanah } \\
\text { Nusantara }\end{array}$} & • MFI Jawa Tengah; & \multirow[t]{3}{*}{ MFI Practioner } & \\
\hline & & & - Cooperation- Nusa Makmur & & \\
\hline & & & Investama & & \\
\hline \multirow[t]{2}{*}{2} & \multirow[t]{2}{*}{ Muhammad Sigit } & President Director; & Chairman: & CEO - Rural Credit; & IF-02 \\
\hline & & Bank Sleman & $\begin{array}{l}\text { - The Association of Regional } \\
\text { Banks }\end{array}$ & MFI Practioner & \\
\hline \multirow[t]{4}{*}{3} & \multirow[t]{4}{*}{ Bagus Hudoyono } & \multirow{4}{*}{$\begin{array}{l}\text { Vice Director of Business } \\
\text { and Operations; } \\
\text { Bank Sleman }\end{array}$} & CIMB Niaga Bank: & \multirow[t]{4}{*}{ CEO - Rural Credit; } & \multirow[t]{4}{*}{ IF-03 } \\
\hline & & & - Area Manager, & & \\
\hline & & & - Commercial Linkage & & \\
\hline & & & $\begin{array}{l}\text { - Product Management, and } \\
\text { Development Head }\end{array}$ & & \\
\hline \multirow[t]{2}{*}{4} & \multirow[t]{2}{*}{ TM. Zakir Machmud } & & \multirow[t]{2}{*}{$\begin{array}{l}\text { Special Advisor to Industry Min- } \\
\text { istry, Republic of Indonesia }\end{array}$} & & \multirow[t]{2}{*}{ IF-04 } \\
\hline & & $\begin{array}{l}\text { Center for SME; Fac- } \\
\text { ulty of Economics and } \\
\text { Business, University of } \\
\text { Indonesia }\end{array}$ & & Researcher & \\
\hline \multirow[t]{3}{*}{5} & \multirow[t]{3}{*}{ Henry C. Wijaya } & President Director; & Directors: & SME's Practioner; & \multirow[t]{3}{*}{ IF-05 } \\
\hline & & $\begin{array}{l}\text { Dharma Bhakti Astra } \\
\text { Foundation }\end{array}$ & - Toyota Astra Motor & Consultant & \\
\hline & & & - Astra International & & \\
\hline
\end{tabular}


Jenri et al.

\begin{tabular}{|c|c|c|c|c|c|}
\hline 6 & Bambang Setyatmojo & $\begin{array}{l}\text { Vice Director of Business } \\
\text { for SME; } \\
\text { Bank BNI Co. Ltd. }\end{array}$ & $\begin{array}{l}\text { Bank BNI Co. Ltd: } \\
\text { - Vice Director of Business for } \\
\text { SME }\end{array}$ & $\mathrm{CEO}-$ Bank & IF-06 \\
\hline 7 & Budi Hanoto & $\begin{array}{l}\text { Vice Director of the } \\
\text { Indonesian SMEs Devel- } \\
\text { opment; } \\
\text { Central Bank of Indonesia }\end{array}$ & $\begin{array}{l}\text { Central Bank of Indonesia: } \\
\text { - Head of Regional Office, } \\
\text { Yogyakarta }\end{array}$ & Regulator & IF-07 \\
\hline 8 & SubiaktoTjakrawerdaya & $\begin{array}{l}\text { Indonesian Ministry of } \\
\text { SMEs; } \\
\text { Former Minister from } \\
1993 \text { to } 1998\end{array}$ & $\begin{array}{l}\text { The Founder and Chairman: } \\
\text { • Damandiri Foundation }\end{array}$ & Regulator & IF-08 \\
\hline 9 & Edimon Ginting & $\begin{array}{l}\text { Deputy Director for } \\
\text { Economic Research and } \\
\text { Regional Cooperation } \\
\text { Department; } \\
\text { Asian Development Bank } \\
\text { (ADB) }\end{array}$ & $\begin{array}{l}\text { Researcher and Professor } \\
\text { - Gadjah Mada University } \\
\text { - Indonesia University }\end{array}$ & $\begin{array}{l}\text { CEO - World Bank; } \\
\text { Academician; } \\
\text { Researcher }\end{array}$ & IF-09 \\
\hline 10 & Supardi Santoso & $\begin{array}{l}\text { Vice Director of Business } \\
\text { for SMEs; } \\
\text { Bank BRI Co. Ltd. }\end{array}$ & $\begin{array}{l}\text { Bank BRI Co. Ltd.: } \\
\text { • Head of Partnership Division }\end{array}$ & CEO - Bank & IF-10 \\
\hline 11 & Tulus TH. Tambunan & $\begin{array}{l}\text { President Director; } \\
\text { Research Center for SMEs } \\
\text { Development (CISBUCS) }\end{array}$ & $\begin{array}{l}\text { Indonesian Chamber of Com- } \\
\text { merce and Industry: } \\
\text { - Chief of Research Department }\end{array}$ & $\begin{array}{l}\text { Academician; } \\
\text { Researcher }\end{array}$ & IF-11 \\
\hline 12 & Teten Masduki & $\begin{array}{l}\text { Minister; } \\
\text { The Indonesian Ministry } \\
\text { for Cooperatives and } \\
\text { SMEs }\end{array}$ & $\begin{array}{l}\text { Presidential Office, Republic of } \\
\text { Indonesia: } \\
\text { - Chief of Staff }\end{array}$ & Regulator & IF-12 \\
\hline 13 & Benny Soetrisno & $\begin{array}{l}\text { Chairman; } \\
\text { Indonesian Chamber of } \\
\text { Commerce and Industry }\end{array}$ & $\begin{array}{l}\text { Ministry of Industry, Republic of } \\
\text { Indonesia: } \\
\text { - Special Advisor } \\
\text { Board of Commissioner: } \\
\text { - Apac Inti Corpora }\end{array}$ & $\begin{array}{l}\text { Business Owner; } \\
\text { CEO - Listed Firm; } \\
\text { Board of Director; }\end{array}$ & IF-13 \\
\hline
\end{tabular}

point. In other words, the authors consider the information to be sufficient (Saunders et al., 2018). Thus, this study selects informants who could be adequately represented by this research in assuming that their knowledge is representative enough to allow us to evaluate this research case (Aldiabat and Le Navenec, 2018). Therefore, the authors could stop the data collection process, and the next informant would not need to be interviewed if the three prior informants provided the same data. In the in-depth interviews, this study considers trustworthiness to mean judging the reliability, credibility, and validity, based on this study's critical perspective. Finally, the inference of this study is carried out using pieces of the collected information from the in-depth interviews, based on the correspondent inference theory and social comparison theory. This study, finally, considers the meaning, rules, and formulations, including relationships between the model's constructs and its results. It, then, refers to the normative standards for inferencing procedures. The final step is to reach a conclusion that is based on the authors' critical reasoning. 
The qualitative stage in this research performs validity and reliability tests to ensure the robustness of the information and the data's interpretation (Creswell, 2014). At this stage, this research conducted a validity test to determine the findings' accuracy in respect of the highly standardized research procedures. Meanwhile, reliability tests are also performed to prove that the approach adopted by the researchers has been consistent and independent. In other words, the authors have reduced their subjectivity and bias regarding the research object (Gibbs, 2007). However, this study assumes that experiential backgrounds influence researchers' perspectives. Thus, the researchers' experiential knowledge is considered more important than these instruments (Creswell, 2014). Based on these considerations, the validity test is conducted.

This study conducts the validity test with a variety of approaches to increase the accuracy of the findings (Creswell, 2014). It applies to two methods. First, the sources' triangulation searches for the data's regularities through cross-checking the data collected (O’Donoghue and Punch, 2003). Meanwhile, Creswell (2014) explains that triangulation of the data, collected from different sources, could build a coherent justification for the research object. This is intended to increase the research's validity. Thus, we apply two models, which are the sources' triangulation and in-depth interviews with regulators, practitioners, and academicians. Additionally, we use specific triangulation techniques, including in-depth interviews, documentation, and observation. To determine the confidence level, this research performs member checking of the data. This step is to ensure the accuracy of the qualitative findings by bringing the research transcripts back to the informant. Thus, the informant could assess the appropriateness of the research- ers' interpretations, in case the in-depth interviews could not capture the information. In this phase, the informant can add more material that the interviews lacked, or correct inaccurate information (Creswell, 2014).

\section{Lessons Learned}

In this section, we elaborate on the current practices of Indonesian regulators, MFIs, and rural credit (RC) institutions in serving, facilitating, and controlling Indonesian SMEs. We decompose the content in the statements which were collected from the indepth interviews, using the social correspondent and social comparison theories. We finally classify these collected excerpts into six loaded concepts for policymaking as follows.

\section{Financial Capital: Not a Primary Preference}

This study collects three excerpts regarding the standing of Indonesian SMEs with respect to social networking, social cognition, organizational readiness, and readiness for change. In other words, this study shows that the financial aspect is not the primary strategy for SMEs to enhance their business processes. Indonesian SMEs need social networks and social cognition, which are used to improve their growth opportunities, business capabilities, and dynamic scalabilities (Boudreaux et al., 2019; Chen et al., 2019; Mehreen et al., 2019; Oo et al., 2018; Wang et al., 2019). These social networks and social cognition theories affect the SMEs' organizational readiness and readiness for change, especially by boosting their commitment and innovativeness (Coleman et al., 2019; Heckmann et al., 2016; Lizar et al., 2015; Puklavec et al., 2018; Weiner, 2009). This study, additionally, succeeds in collecting three pieces 
of evidence from the informants as follows:

Currently, the financial aspect is not a real need for SMEs; however, it is necessary. During my 20 years of experience in managing SMEs, I decided that the financial aspect is necessary for SMEs; however, it is not an essential parameter. I do not know why - in all practices_-people always conclude that the need for capital and debt collaterals are still dominant (IF-01-1).

These Indonesian SMEs should not be facilitated with additionally invested capital to have growth opportunities. Instead, they should enbance their capacities and scalabilities. The Government of Indonesia is not only belping these SMEs with financial loans and aid but also with education (IF-02-1; -3).

We have never conducted a ranking study, but we know that the aspect of the SMEs' capital is only a part of many variables, which are marketing, innovation, technology, and everything. However, I see in almost every discussion that financial credits appear to be needed. I talk about these SMEs under 1 billion that need some help from our bank. Indeed, access to financial capital is not a big problem anymore due to large SMEs. When I speak about possible support for SMEs, I cannot possibly speak anymore about additionally invested capital on its own (IF-06-1).

This study infers from these statements that most Indonesian SMEs have focused on their social networks. They have achieved a dynamic adaptation by establishing and acquiring social networks (Chen et al., 2019; Mehreen et al., 2019; Yamin and Kurt, 2018; Zhou et al., 2007). It means that Indonesian SMEs have achieved a high level of learning, information dissemination, communication, coordination, and knowledge management, which is used by them for networking with other SMEs. This study also considers SMEs' networking without neglecting the financial capital aspect. Meanwhile, it verifies that the Indonesian SMEs have ensured their sustainability; that is, they have acquired social cognition in terms of their level of skills, expertise, and competency. However, this social cognition should be maintained, by themselves, to support their businesses. In other words, these SMEs have realized their organizational self-efficacy (Bandura, 1988, 1989; Boudreaux et al., 2019; Wang et al., 2019). This study, therefore, concludes that Indonesian SMEs have developed dynamic capabilities, and consequently, their organizational readiness and readiness for change.

The authors infer that Indonesian SMEs have built all the required elements of social networks and social cognition since financial capital is not the primary concern. This phenomenon has consequences for the MFI, RC, and Indonesian regulators, with respect to a potential future curriculum that makes the SMEs upgrade their business activities. This curriculum should blend organizational innovativeness, marketing, and the use of information and communications technology (Zarnowitz and Braun) to increase the SMEs' future dynamic capabilities. Additionally, it will support Indonesian SMEs in overcoming future uncertainties due to their intangible endowment knowledge (Rogers, 1961). By possessing their dynamic capabilities, these SMEs could ascertain their future growth and learn how to evade failure (Noel et al., 2019). This study, therefore, concludes that Indonesian regulators should not consider more financial policies for these SMEs. Instead, they have to focus on enhancing social networks and social cognition to improve the SMEs' dynamic capabilities, thus supporting their growth opportunities.

\section{Too Many Agencies Involved in En- bancing the SMEs}

This study acknowledges that most Indonesian SMEs have been controlled and 
Gadjah Mada International Journal of Business - Jan.-April, Vol. 22, No. 1, 2020

regulated by various laws produced by specific agencies. Owing to the various regulations, these SMEs could not focus on their bonding to improve their businesses. These SMEs, consequently used a traditional business model, since they have to comply with the characteristics of certain business models (Koenig and Eagly, 2014). This study infers that these SMEs exhibit behavior based on their business characteristics, which does not allow them to achieve organizational readiness. This study explains that SMEs recognize and then perceive a comfortable environment, resulting in a low organizational readiness (Commerford et al., 2018). From other perspectives, SMEs get their low organizational innovativeness because of their behavioral role, which is limited by the restrictions in many of the regulations (Hamilton et al., 2009; Kaplan and Ravenscroft, 2004; Koenig and Eagly, 2014). In their development, these SMEs face difficulties due to the regulations that impose many restrictions and rules on them, thus causing difficulties in developing their organizational commitment and efficacy. For example, the following three comments from the indepth interviews illustrate this difficulty.

Too many agencies are involved in controlling and regulating SMEs. We should, perhaps, have a national board that controls, executes, and governs SMEs, while the others should not be involved (IF-01-4).

Most governmental institutions work with pathways themselves, while never meeting. These institutions usually work neither convergently nor divergently. They conduct their governmental functions, responsibilities, and tasks for those SMEs in a parallel manner. Thus, their work system is only mechanical (IF-04-8).

Local governments should make investment regulations easier for SMEs so that they could expand employment opportunities. The development of SMEs, as well as the creation of employment opportunities, could be measured by these local governments. It is not a concern for local governments to absorb the regional budgets and to make some regional regulations. Perhaps, the less a localgovernment intervenes with regional regulations; the more these SMEs succeed (IF-13-7).

This study analyzes the statements of IF-01-04, IF-04-8, and IF-13-7, who said that Indonesian SMEs face unnecessary regulations because of too many variations. It finds that SMEs face probable failure when other problems challenge them (Boivie et al., 2015; Suls et al., 2002). Moreover, this study considers that regulations or agencies control every aspect of the SMEs. It also shows that not only do these regulations not support each other, but they also overlap. We, therefore, conclude that most Indonesian SMEs tend to choose lenient references concerning their situational involvement (Criaco et al., 2017). It means that all the SMEs are quantitively-regulated firms, resulting in them having difficulties when trying to upgrading their businesses. Evidently, most Indonesian SMEs are faced with some procedural constraints when trying to enlarge their business capacities.

To tackle this problem, we argue that the GoI should simplify regulations by making only one agency the leading authority, thus making it easier for these SMEs to achieve their agendas due to singularity bonding. This study, moreover, argues that the leading authorized regulator could control and manage these SMEs" future directions. Additionally, the leading authorized regulator could detect and then recognize the SMEs' business risks nationally. In other words, this regulator could direct all the SMEs onto a convergent orientation in alignment with the national goals. Moreover, the regulator can get the function, responsibility, and task domains without issuing contradictory directions. 
Jenri et al.

Knowledge Supremacy for the SMEs' Empowerment

Kraus and Tan (2015) and Hamid et al., (2015) all established that the relationships among social networks, social cognition, organizational readiness, and readiness for change support the knowledge supremacy of SMEs. In addition, other studies argue that these relationships enhance knowledge supremacy (Fatoki, 2011; C. Jones and Volpe, 2011; Lee et al., 2010). Similarly, we argue that SMEs' knowledge acquisition is useful for achieving a higher level of business for the Indonesian SMEs that have the capability to recognize dynamic environmental changes. This study also shows that low social cognition, social networks, and international pressures could reduce the potential power of Indonesian SMEs. To overcome this difficulty, the GoI has to support knowledge empowerment for these SMEs. This article collects some comments regarding this issue as follows:

I argue that innovativeness is more critical than financing. By all means, the Government of Indonesia should not consider the need for SMEs' financial capital; instead, it should consider these SMEs' innovativeness in terms of what they have produced (IF-03-1;-3).

The Indonesian SMEs are not only supported by financial capital, but they can also continue to grow. If the Indonesian SMEs have not increased their capacities, and if they are in the domestic market only, how can they make their products more attractive and efficient? How do their marketing strategies work? Sometimes, they could produce but face difficulties in marketing. We sometimes collaborate with relevant agencies, provide knowledge about how SMEs can market their products correctly, and make good packaging to be more attractive (IF-02-1).

Mentoring, coaching, business clinics, consultations, and business gatherings for SMEs are essential problems for the Government of In- donesia. These types of empowerment policies should be adopted by the Government to fulfill their social cognition of the SMEs (IF-04-13).

I love the ease of access to potential creditors. Without support from many friends for the SMEs, it would be useless. However, for me, although it is prevalent to belp SMEs only with financing, funding is a small thing, but other aspects such as market access, or intangible capital acquisitions should be considered and taught to Indonesian SMEs. It means that these SMEs should change their mindset, as the mindset is the spirit of business entrepreneurs (IF-06-2; -5).

Competitive advantages for SMEs should become a school of thought. This thought is known as economic transformation. Therefore, it is an intangible capital that is more important than knowledge, including innovativeness, good moral character, and networking (IF-08-04).

They have many local entrepreneurs whose orientation is out in their authorizations. The most important thing, especially in China, is entrepreneurship. They have more advanced SMEs and a better business instinct than the Indonesian SMEs. Korean SMEs export their products everywhere due to their knowledge (IF-09-1).

This study infers from those statements that the acquisition of knowledge is a primary factor that should be adopted by the GoI to enhance SMEs. It shows that the providers of IF-03-1, -3, and IF-02-1 recommend enhancing social cognition to increase the innovativeness (Fatoki, 2011; C. Jones and Volpe, 2011; Lee et al., 2010) of the Indonesian SMEs. Additionally, IF-08-4 and IF-09-1 explain that Indonesian SMEs should boost their creativity, to achieve their highest level of innovativeness (Chen et al., 2019; Coleman et al., 2019; Dabholkar, 1996; Norman, 1998; Walker et al., 2016). This study supports the Indonesian SMEs' innovativeness in searching for opportunities to maintain and sustain 
Gadjah Mada International Journal of Business - Jan.-April, Vol. 22, No. 1, 2020

their businesses. It, moreover, demonstrates the dynamic adaptation for Indonesian SMEs' earning power. Overall, all the comments conclude that MFIs, RC, and the regulators should place knowledge supremacy as the catalyst to reinforce the international competitiveness of Indonesian SMEs.

The authors infer that the Indonesian regulators should take into account that knowledge supremacy is the first trigger to enhance the SMEs' organizational readiness and their readiness for change. This article argues that knowledge supremacy itself is the SMEs' social capital, which is used to improve their awareness and their understanding of business dynamics (Liljander et al., 2006; Loyd and Gressard, 1984; Munger and Loyd, 1989; Scheier and Carver, 1987). With the current standing of knowledge supremacy, the Indonesian SMEs can also anticipate environmental business dynamics, so that they improve their performance. If the Indonesian regulators impose regulations for knowledge supremacy on the SMEs, the SMEs can enhance their business agility. Moreover, we suggest that Indonesian SMEs demonstrate an optimistic commitment (Coleman et al., 2019; Puklavec et al., 2018) Thereby, the Indonesian SMEs can achieve higher levels of competitiveness, in comparison with other countries.

\section{Shifting the Balance for SMEs' Orga- nizational Readiness}

The relationships among social networks, social cognition, organizational readiness, and readiness for change formulate a new balance for these Indonesian SMEs. Gupta et al. (2006) suggest organizational continuance to adapt to environmental changes. This infers that a shift in balance occurs when SME organizational behavior changes in terms of beliefs, attitudes, and trust (Philip and McKeown, 2004b). The authors argue that a shift in the balance of Indonesian SMEs will probably occur due to knowledge acquisition. This acquisition causes organizational SMEs to have firmer beliefs, attitudes, and greater trust. The following five transcripts from the research's respondents discuss this issue.

The standardization of the SMEs' capacities is essential to face global competition. Right now, foreign products are free to enter our country while our citizens look for imported products that are cheaper than local products. It is a chaotic problem (IF-02-5).

It is not just knowledge empowerment, but the cultural mindset. The cultural mindset must be changed first so that it can trigger their motivation. Sometimes, the second important thing is improving the SMEs' education and training of their employees (IF-04-1).

Governmental institutions should know the achievement level of SMEs in their respective stages. Many SMEs are in different stages, which are influenced by the policies of the governmental regulators. This institution, however, agrees that innovativeness and networks will determine the SMEs' success (IF-07-1).

Wherever there is culture, how to change it must follow the right approach. Why should we go to Singapore? We can follow the Singaporean culture. That is why the Government of Indonesia must create a new culture. The regulations must create a new system. With proper rules, everyone can participate adequately. Our SMEs must also be like that. You should create a system that enables everyone to become an entrepreneur. The Government's income is enough to finance entrepreneurship from the taxes itself. It should be partly returned to empower the Indonesian SMEs (IF-09-3).

In terms of the SMEs' buman resources, it is a cultural system. To improve the Indonesian SMEs, the most important is social empowerment. It is the most important thing when we talk about anything, the most importantpeople, including the SMEs' executives and 
officers. In particular, the SMEs, which have started in the middle class, they have to innovate (IF-09-4).

This study analyzes the transcript of IF-07-1, who states that the initial point of the existing balance should be identified, thus identifying the endpoint after the shift. This endpoint is the newly developed culture created by the GoI. This culture will be used to enhance the dynamic capabilities of Indonesian SMEs, which have beliefs, attitudes, and trust (Philip and McKeown, 2004b). Overall, it could be founded on the statements of IF-02-5, IF-04-1, IF-09-3, and IF-09-4. In other words, the GoI should strengthen these SMEs with industry-wide regime shifts (Biggs et al., 2009). Thus, the Indonesian regulators have to make the SMEs the subject of the industry, rather than the object of development. With this strategy, the Indonesian regulators can create stability, sustainability, growth, and improvement in the future.

This article infers that the GoI could develop the shift in the balance of the SMEs to change their need for knowledge. The regulators, furthermore, can require the SMEs' executive officers to capture their organizational readiness for change. Therefore, the Indonesian regulators have to manage knowledge dissemination, communication, collaboration, and innovation (Mehreen et al., 2019; Yamin and Kurt, 2018; Zhou et al., 2007) across the SMEs. Furthermore, they should standardize the minimum knowledge required to empower SMEs. By standardizing experiential knowledge, Indonesian SMEs can improve their innovativeness and competitiveness (Chen et al., 2019; Coleman et al., 2019; Dabholkar, 1996; Norman, 1998; Walker et al., 2016). Finally, this study shows that Indonesian SMEs could shift into a new paradigm. This means that Indonesian SMEs could move forward to become organizationally ready for changes that are different from those before. The differential capabilities are that those SMEs acquired social networks, social cognition, and organizational readiness. This study, furthermore, explains that the Indonesian regulators should take into account these dimensioned capabilities to construct the policy.

\section{The Need for An Omnibus Law for SMEs}

The authors note that the GoI, through its ministries (agencies), control and manage the SMEs. In other words, Indonesian SMEs are controlled and managed by multiple agencies with multiple regulations. This article, therefore, concludes that Indonesian SMEs cannot immediately enter the mature business class because of the existence of too many institutions and regulations. This study argues that the need for an omnibus law is the logical result of all the previous discussions. An omnibus law could consolidate various regulations, which have become excessively complicated. The omnibus act can ensure the simplification of many regulations, and that there is no overlap among them. This study suggests that an omnibus law is needed to reduce the gaps between existing practices and expected outputs (Carreiro and Oliveira, 2019; Kumar and Singh, 2019; Zhang, 2018). Nevertheless, these gaps are useful for identifying, internalizing, and evaluating the inadequacies in all the existing regulations, which are accommodated in the new omnibus law (Khurshid et al., 2018; Noel et al., 2019). This study presents the following comments that explain the need for an omnibus law for Indonesian SMEs.

Owing to the existence of dichotomy in some governmental agencies, they are either involved in 
Gadjah Mada International Journal of Business - Jan.-April, Vol. 22, No. 1, 2020

convergence or divergence in controlling and regulating SMEs; that is why the Government of Indonesia should adopt an omnibus law (IF-07-7).

We have heavy responsibilities to create job opportunities. The Government of Indonesia has to develop an omnibus law, which will be used to create and expand employment opportunities. This responsibility also facilitates and supports the growth of SMEs. A national leader has to achieve these policies (IF-13-7).

The Government of Indonesia, through the Ministry of SMEs, had designed an omnibus law that imposes specific policies to prevent the overlapping of regulations and ascertains fairness and parsimony. It means that the Government has to consolidate all the current rules to formulate this omnibus law, which should also evaluate the relevance of them, and whether any irrelevant regulations should be eliminated (IF-12-02).

Researchers argue that an omnibus law should be based on the doctrine that the purpose defeats the (existing) laws. Nevertheless, this doctrine should not be interpreted as the purpose justifies the means. From the excerpts of IF-07-7, IF-13-7, and IF-12-02, this study establishes the absolute need for an omnibus law. With this omnibus law, the GoI could fill the gaps in the existing regulations. The most important thing for the Indonesian regulators is that they should determine what output level could be achieved nationally by this omnibus law (Carreiro and Oliveira, 2019; Kumar and Singh, 2019; Zhang, 2018). The omnibus law is to identify, internalize, and evaluate all the existing contributions (Khurshid et al., 2018; Noel et al., 2019) from all Indonesian SMEs if the regulators succeed in creating it. This study finally concludes that the Indonesian regulators should define the SMEs' production roles using an industry-wide concept as well as a revolutionary concept within this omnibus law.

This study, therefore, shows that the existence of an omnibus law would be associated with a shift in the current balance.
This association supports the SMEs' readiness for change. It explains that this omnibus law will also support the Indonesian SMEs in realizing their best performance (Khurshid et al., 2018; Noel et al., 2019) through organizational commitment and self-efficacies. The authors argue that for innovation, most SMEs' executive officers could refer to the regulation that boosts creativity due to the relationship between knowledge and innovation (Carreiro and Oliveira, 2019; Kumar and Singh, 2019; Zhang, 2018). From the perspective of risk, the Indonesian regulators should control the SMEs with an omnibus law because it could raise the associated control risk in comparison to the multiple institutions with their various regulations. In other words, the Indonesian regulators have a low detection risk due to the uni-parameter.

\section{Strategies for Achieving Optimal Dis- tinctiveness}

This study considers that the Indonesian MFI, RC, and regulators have pursued some strategies for achieving the optimal distinctiveness of SMEs. Additionally, it analyzes all the ideas of the research's informants, who probably focus on realizing optimal distinctiveness. It means that the Indonesian SMEs, during their evolution era, followed paths that did not allow them to exist independently from others. In other words, Indonesian SMEs need to be part of larger groups to survive, such as industry groups. These industrial groups are used as a fundamental basis for their growth and prosperity. In some industries, the Indonesian SMEs have optimal (positive) characteristics that can deliberately strengthen their motivations. Thus, they could achieve distinctiveness through the strength of their social identity (Brewer, 2003), meeting industrial needs, and satisfy- 
ing the industry's psychological needs (Brewer, 1999, 2003). The following transcripts from some informants explore this issue.

We probably need an economic development board, such as in Singapore. Why does the Ministry for Cooperatives and SMEs only introduce regulations? This Ministry should focus on the business processes of SMEs. SMEs' businesses do not use bureaucratic concepts. At least, this Ministry should belp these SMEs to sell their products abroad (IF-01-5).

The existing policies are that 'one law fits all,' indicating that the Government of Indonesia does not understand what SMEs and their characteristics are. The governmental policies, therefore, do not consider their characteristics and their current stage (IF-04-9).

Dharma Bhakti Astra Foundation offers to educate and train some SMEs if they can meet the quality control design of products, which is demanded by the corporate listed firms. We also give cost tolerances for SMEs since they are in small economies of scale. However, we believe that corporate listed firms should be supplied by trustwortby SMEs (IF-05-6).

The industrial policies should be based on axiological concepts that are outward-looking, to develop comparative advantages; thus, the Indonesian SMEs can get their competitiveness internationally. The absolute benefits of economic resources support these comparative advantages and competitiveness. It, therefore, could be used to compete globally. These economic resources, moreover, are not owned by others (IF-08-3).

I think the most relevant policies related to the results of this study are: policies that support the SMEs' ability to innovate, policies that improve entrepreneurship development, and policies that help SMEs expand their networks (IF-11-2).

The Government of Indonesia's experience limits information on the actual problems regarding the challenges faced by SMEs. Therefore, the research results from some universities need to be distributed to the Government, including either the
Ministry for Cooperatives and SMEs or the $\mathrm{Na}$ tional Development Planning Agency (IF-11-6).

The development of core ideas is at the forefront of the economic development of these SMEs. The ministry responsible for SME needs belp from some universities to formulate a national policy for SMEs. The national strategy should probably focus on the potential future development of these SME first, particularly the use of high ICT (IF-12-14).

This study analyzes the results of the indepth interviews in the current excerpts of IF-01-5 and IF-04-9 from the MFIs, RC, and the ministry responsible for SMEs. It infers that the ministry should not only focus on the practical needs of SMEs, such as education and training. Additionally, the ministry needs assistance in bridging the gap between theory and practice (IF-08-3, IF-11-2; -6, and IF-1214), so that its policies can achieve optimal distinctiveness for the Indonesian SMEs (Brewer, 1991, 2003; Sheldon and Bettencourt, 2002; Zhang, 2018). In other words, comprehensive and coherent policies can support Indonesian SMEs to gain innovativeness, develop entrepreneurship, and expand their networks (Coleman et al., 2019; Puklavec et al., 2018). Moreover, we highlight that an innovation process is needed to influence the executive officers' knowledge of all SMEs (Rogers, 1961).

First, this study shows that an omnibus law could not be separated from achieving optimal distinctiveness and reaching new equilibrium points, which are inseparable from the replacement, elimination, or expansion of the organizational and industrial structure (Greenwood and Hinings, 1996; Gupta et al., 2006; Lyytinen and Newman, 2008). The interviews revealed that ministries are more useful when they play a functional role, but not a regulatory role. This study argues that an omnibus law needs to be adopted to achieve optimal distinctiveness. Furthermore, it highlights the impor- 
Gadjah Mada International Journal of Business - Jan.-April, Vol. 22, No. 1, 2020

tance of eliminating the gap between theory and practice through collaboration with universities' research outputs (Carreiro and Oliveira, 2019; Kumar and Singh, 2019; Zhang, 2018). Second, this study suggests that the SMEs' achievements in social cognition and internet-working are the key to their success, along with the use of Information and Communications Technology (ICT) to prepare for the fourth industrial revolution. This achievement, furthermore, indicates that dynamic knowledge plays an essential role in developing the SMEs' future optimal distinctiveness.

\section{The Study's Findings}

This study proposes a basic and coherent strategy that should be adopted by Indonesian regulators to empower Indonesian SMEs. This underlying policy highlights the linkage role of knowledge supremacy (Coleman et al., 2019; Puklavec et al., 2018), the strategic role of an industry-wide regime, and the quest for Indonesian SMEs' empowerment. Policies at this level are essential and should contain the necessary conditions for realizing concepts and theories (Carreiro and Oliveira, 2019; Kumar and Singh, 2019). Thus, this comprehensive policy still needs to be further pursued through three detailed sub-policies that can be practiced directly by MFIs, RC, and regulators. Likewise, detailed sub-policies cover the more distinctive traits that can be increasingly realized in real practices. To facilitate their readability, Figure 2 summarizes the suggested policies.

This study recommends policies that could be implemented by MFIs, RC, and regulators for empowering the Indonesian SMEs

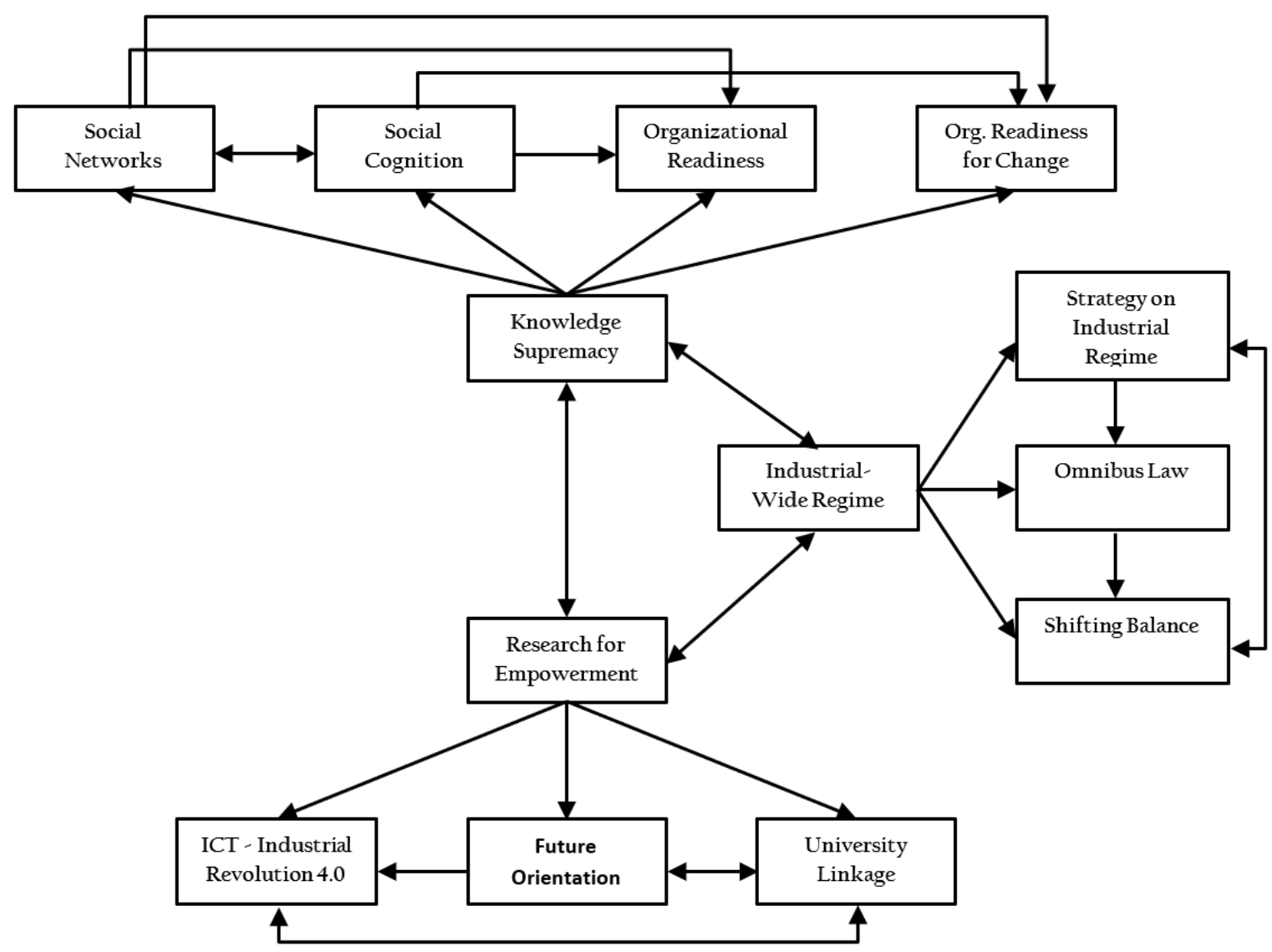

Figure 2: Detailed Study of Map to Formulate Governmental Policies 
that have entered a new phase. The first policy is the establishment of knowledge supremacy as an empowering tool. The main form or type of knowledge is related to the organizational readiness and readiness for change of the Indonesian SMEs (Fatoki, 2011; Lee et al., 2010). Meanwhile, social networks and social cognition encourage the development of organizational readiness and readiness for change. In other words, the four constructs can elevate the position of Indonesian SMEs so they can acquire dynamic capabilities and achieve increasingly higher competitiveness. This study concludes that Indonesian regulators have to focus on the real concepts, which should be used to elevate these SMEs by highlighting the importance of knowledge as the asset with the highest value in the future. This study also concludes that knowledge's mastery has become intangible capital for the Indonesian SMEs' executive officers (Rogers, 1961). Moreover, knowledge supremacy could direct SMEs to deal with future economic uncertainties. In other words, the empowerment of Indonesian SMEs depends on their adaptive scalability and agility.

The second policy concerns the role of SMEs in the industrial sector, and they should not be viewed only as objects developed nationally. It means that the Indonesian regulators should adopt a market-wide shifting strategy for SMEs. In this study, we intend to dismiss all types of development programs that consider SMEs as objects. Additionally, we take the market-wide regime shifting strategy as a step for empowering SMEs into the future. However, this study requires a parallel axis for this empowerment, which is the development of a revolutionary model with an omnibus law. It means that an omnibus statute will empower Indonesian SMEs when accompanied by a market-wide regime shifting strategy. Consequently, the development of Indonesian SMEs could achieve a new shifted balance, confirming the significance of the two elements (Biggs et al., 2009; Gupta et al., 2006; Philip and McKeown, 2004a). In other words, this study concludes that future policies regarding Indonesian SMEs must be based on three elements that must be played simultaneously. The three components are the structure of the industry-wide regime, the omnibus law, and the strategy of a shift in balance.

The third policy complements the first and second policies. It focuses on research for the future empowerment of Indonesian SMEs. This policy must create a linkage with the output of academic research to enhance Indonesian SMEs. Moreover, this policy is future-oriented, as it can transform the Indonesian SMEs by improving their dynamic capabilities, adaptive structure, competitiveness, and agility (Noel et al., 2019; Rogers, 1961; Wang et al., 2019). Likewise, this third policy has to be complemented by incorporating ICT into Indonesian SMEs. The integration of ICT in the Indonesian SMEs' business processes is explicitly created to prepare for the fourth industrial revolution. In other words, this study states that the research for SMEs empowerment has three interrelated elements, which are the universities as actors, future orientation, and ICT's incorporation into the SMEs' business processes to prepare for and utilize the fourth industrial revolution.

\section{Conclusion, Limitations, And Future Research}

This study investigates the matching and mismatching strategies, controls, and regulations that are adopted by the regulators of Indonesian SMEs. By exploring the current strengths and standing of the Indo- 
Gadjah Mada International Journal of Business - Jan.-April, Vol. 22, No. 1, 2020

nesian SMEs, the future orientation of these Indonesian SMEs, and the need for an omnibus law for these SMEs, we demonstrate the novelty of this research. To investigate the research goals, the authors use the two theories of correspondent inference and social comparison to understand the problematic sluggishness of Indonesian SMEs. This study considers four factors, which are social networks, social cognition, organizational readiness, and readiness for change, to evaluate and analyze the current conditions of Indonesian SMEs. It, finally, employs a qualitative research method by conducting in-depth interviews with 13 informants who are upper-level executive officers in diverse Indonesian institutions to collect the data.

This study succeeds in constructing six loading factors that are financial capital, which is not a primary preference, that too many agencies are involved in enhancing knowledge supremacy, the shifting balance, the need for an omnibus law, and achieving optimal distinctiveness. From these six lessons learned, which had been discussed, we identify policies that could be used by Indonesian regulators in the future. We found three primary policies: the linkage role of knowledge supremacy, the strategic role of an industry-wide regime, and the academic research for Indonesian SMEs' empowerment. Finally, we divide the basic policy into detailed sub-policies that can be practiced directly by MFIs, RC, and the Indonesian regulators. Thereby, this study expects that the empowerment of Indonesian SMEs can be achieved through adaptive scalability and agility. The second policy is the combined structure of an industry-wide regime, an omnibus law, and the strategy of shifting the balance. The third one is promoting academic research, with universities as actors, future orientation, and incorporating ICT into the
SMEs' business processes to prepare for and utilize the fourth industrial revolution.

Nevertheless, our study has three limitations. The first limitation is derived from the interactions between knowledge supremacy, the strategy of an industry-wide regime, and promoting research for SMEs' empowerment. This study concludes that SMEs' empowerment could be achieved if there is no high power distance between the Indonesian regulator and SMEs' executive officers. In other words, the existence of a power distance will weaken the transformation process of SMEs' empowerment, thus supporting the argument that the combined set of knowledge supremacy, implementation of strategy, and successful research are based on Western culture, which has a low power distance. Thus, it would be interesting for the next study to investigate the sluggishness of SMEs' empowerment from the perspective of the high institutional power distance that exists in Indonesia. The second limitation is the deacceleration impacts of political agendas, such as the political struggle to be an authorized institution. This study found that the SMEs' empowerment occurred temporarily and incidentally in Indonesia. This limitation is also supported by the barriers to adopting major and radical reforms such as glasnost and perestroika. Finally, this limitation could be shown with the delay in the development of an omnibus law for SMEs. Future research could investigate the impact of the new omnibus law for SMEs, which has already been approved by the Indonesian Parliament.

The third limitation is that this study does not consider the levels of Indonesian SMEs, and does not take into account the diverse levels among these SMEs in each region of Indonesia. This study, moreover, measures the need for knowledge supremacy, the 
Jenri et al.

implementation of strategy with an industry-wide regime, and the linkage to academic research using a national unit analysis, and not an organizational unit analysis, indicating that this study has a bias toward the upper level of the national economy. Finally, the au- thors recognize that this study's results have to be verified with respect to other countries in the world. Therefore, future studies may consider extending this research by expanding the geographical scope and conducting comparisons among different countries.

\section{References}

Aldiabat, K. M., and Le Navenec, C.-L. (2018). Data saturation: The mysterious step in grounded theory methodology. The Qualitative Report, 23(1), 245-261.

Argo, J. J., White, K., and Dahl, D. W. (2006). Social comparison theory and deception in the interpersonal exchange of consumption information. Journal of Consumer Research, 33(1), 99-108.

Aspinwall, L. G., and Taylor, S. E. (1993). Effects of social comparison direction, threat, and self-esteem on affect, self-evaluation, and expected success. Journal of personality and social psychology, 64(5), 708.

Bandura, A. (1988). Organizational applications of social cognitive theory. Australian Journal of Management, 13(2), 275-302.

Bandura, A. (1989). Human agency in social cognitive theory. American psychologist, 44(9), 1175.

Biggs, R., Carpenter, S. R., and Brock, W. A. (2009). Turning back from the brink: detecting an impending regime shift in time to avert it. Proceedings of the National academy of Sciences, 106(3), 826-831.

Boivie, S., Bednar, M. K., and Barker, S. B. (2015). Social comparison and reciprocity in director compensation. Journal of Management, 41(6), 1578-1603.

Boudreaux, C. J., Nikolaev, B. N., and Klein, P. (2019). Socio-cognitive traits and entrepreneurship: The moderating role of economic institutions. Journal of Business Venturing, 34(1), 178-196.

Brewer, M. B. (1991). The social self: On being the same and different at the same time. Personality and social psychology bulletin, 17(5), 475-482.

Brewer, M. B. (1999). The psychology of prejudice: Ingroup love and outgroup hate? Journal of social issues, 55(3), 429-444.

Brewer, M. B. (2003). Optimal distinctiveness, social identity, and the self.

Carreiro, H., and Oliveira, T. (2019). Impact of transformational leadership on the diffusion of innovation in firms: Application to mobile cloud computing. Computers in Industry, 107, 104-113. 
Gadjah Mada International Journal of Business - Jan.-April, Vol. 22, No. 1, 2020

Chen, Y.-S., Lei, H.-S., and Hsu, W.-C. (2019). A Study on the Sustainable Development Strategy of Firms: Niche and Social Network Theory. Sustainability, 11(9), 2593.

Coleman, P. T., Kugler, K. G., Vallacher, R., and Kim, R. (2019). Hoping for the best, preparing for the worst: Regulatory focus optimality in high and low-intensity conflict. International Journal of Conflict Management, 30(1), 45-64.

Commerford, B. P., Hatfield, R. C., and Houston, R. W. (2018). The effect of real earnings management on auditor scrutiny of management's other financial reporting decisions. The Accounting Review, 93(5), 145-163.

Creswell, J. W. (2014). A concise introduction to mixed methods research: SAGE publications.

Criaco, G., Sieger, P., Wennberg, K., Chirico, F., and Minola, T. (2017). Parents' performance in entrepreneurship as a "double-edged sword" for the intergenerational transmission of entrepreneurship. Small Business Economics, 49(4), 841-864.

Dabholkar, P. A. (1996). Consumer evaluations of new technology-based self-service options: an investigation of alternative models of service quality. International Journal of research in Marketing, 13(1), 22.

Fatoki, O. O. (2011). The impact of human, social, and financial capital on the performance of small and medium-sized enterprises (SMEs) in South Africa. Journal of Social Sciences, 29(3), 193-204.

Festinger, L. (1954). A theory of social comparison processes. Human Relations, 7(2), 117-140.

Gawer, A. (2009). Platform dynamics and strategies: from products to services. Platforms, markets, and innovation, 45, 57.

Gibbs, G. R. (2007). Thematic coding and categorizing. Analyzing qualitative data. London: Sage, 38-56.

Gorbachev, M. S. (1996). Mikhail Gorbachev: Memoirs: Doubleday.

Greenwood, R., and Hinings, C. R. (1996). Understanding radical organizational change: Bringing together the old and the new institutionalism. Academy of management review, 21(4), 1022-1054.

Gupta, A. K., Smith, K. G., and Shalley, C. E. (2006). The interplay between exploration and exploitation. Academy of management journal, 49(4), 693-706.

Guyer, J. J., Fabrigar, L. R., Vaughan-Johnston, T. I., and Tang, C. (2018). The counterintuitive influence of vocal affect on the efficacy of affectively-based persuasive messages. Journal of Experimental Social Psychology, 74, 161-173.

Hamid, S., Waycott, J., Kurnia, S., and Chang, S. (2015). Understanding students' perceptions of the benefits of online social networking use for teaching and learning. The Internet and Higher Education, 26, 1-9. 
Hamilton, A., Madison, J., and Jay, J. (2009). Federalist No. 81 The Federalist Papers (pp. 249-254): Springer.

Heckmann, N., Steger, T., and Dowling, M. (2016). Organizational capacity for change, change experience and change project performance. Journal of Business Research, 69(2), 777-784.

Huntsberger, M., and Greenville, S. (2008). Create Once, Play Everywhere: Convergence strategies for public radio in the US.

Jones, C., and Volpe, E. H. (2011). Organizational identification: Extending our understanding of social identities through social networks. Journal of organizational behavior, 32(3), 413434.

Jones, E. E., and Davis, K. E. (1965). From acts to dispositions the attribution process in person perception Advances in experimental social psychology (Vol. 2, pp. 219-266): Elsevier.

Kaplan, S. E., and Ravenscroft, S. P. (2004). The reputation effects of earnings management in the internal labor market. Business Ethics Quarterly, 14(3), 453-478.

Khurshid, M. M., Zakaria, N. H., Rashid, A., Kazmi, R., and Shafique, M. N. (2018). Diffusion of Big Open Data Policy Innovation in Government and Public Bodies in Pakistan. Paper presented at the International Conference on Intelligent Technologies and Applications.

Koenig, A. M., and Eagly, A. H. (2014). Evidence for the social role theory of stereotype content: Observations of groups' roles shape stereotypes. Journal of personality and social psychology, 107(3), 371.

Kraus, M. W., and Tan, J. J. (2015). Americans overestimate social class mobility. Journal of Experimental Social Psychology, 58, 101-111.

Kumar, S., and Singh, B. (2019). Barriers to the international diffusion of technological innovations. Economic Modelling, 82, 74-86.

Lee, S. H., Kim, P.-J., Ahn, Y.-Y., and Jeong, H. (2010). Googling social interactions: Web search engine based social network construction. PLoS One, 5(7), e11233.

Liljander, V., Gillberg, F., Gummerus, J., and Van Riel, A. (2006). Technology readiness and the evaluation and adoption of self-service technologies. Journal of Retailing and Consumer Services, 13(3), 177-191.

Lin, L., and Daim, T. U. (2009). Platform strategy framework for internet-based service development: case of eBay. International Journal of Services Technology and Management, 11(4), 334354.

Lizar, A. A., Mangundjaya, W. L., and Rachmawan, A. (2015). The role of psychological capital and psychological empowerment on individual readiness for change. The Journal of Developing Areas, 49(5), 343-352.

Loyd, B. H., and Gressard, C. (1984). Reliability and factorial validity of computer attitude scales. Educational and psychological measurement, 44(2), 501-505. 
Gadjah Mada International Journal of Business - Jan.-April, Vol. 22, No. 1, 2020

Lyytinen, K., and Newman, M. (2008). Explaining information systems change a punctuated socio-technical change model. European Journal of Information Systems, 17(6), 589-613.

Majid, A., and Yasir, M. (2017). Individual and Work Dynamics Affecting The Determinants of Functional Flexibility in SMEs. Journal of Entrepreneurship in Emerging Economies.

McForan, D. W. (1988). Glasnost, democracy, and perestroika. International Social Science Review, 165-174.

Mehreen, A., Hui, Y., and Ali, Z. (2019). A social network theory perspective on how social ties influence perceived employability and job insecurity: evidence from school teachers. Social Network. Analysis and Mining, 9(1), 25.

Munger, G. F., and Loyd, B. H. (1989). Gender and attitudes toward computers and calculators: Their relationship to math performance. Journal of Educational Computing Research, 5(2), 167-177.

Noel, L., Sovacool, B. K., Kester, J., and de Rubens, G. Z. (2019). Conspicuous diffusion: Theorizing how status drives innovation in electric mobility. Environmental Innovation and Societal Transitions, 31, 154-169.

Norman, D. A. (1998). The invisible computer: why good products can fail, the personal computer is so complex, and information appliances are the solution: MIT press.

O'Donoghue, T., and Punch, K. (2003). Qualitative educational research in action: Doing and reflecting: Routledge.

Oo, P. P., Sahaym, A., Juasrikul, S., and Lee, S.-Y. (2018). The interplay of entrepreneurship education and national cultures in entrepreneurial activity: a social cognitive perspective. Journal of International Entrepreneurship, 16(3), 398-420.

Parker, G., and Van Alstyne, M. W. (2014). Platform strategy.

Philip, G., and McKeown, I. (2004a). Business transformation and organizational culture:: The role of competency, IS, and TQM. European management journal, 22(6), 624-636.

Philip, G., and McKeown, I. (2004b). Business transformation and organizational culture:: The role of competency, IS, and TQM. European management journal, 22(6), 624-636.

Pruitt, D. G. (2015). The evolution of readiness theory Handbook of International Negotiation (pp. 123-138): Springer.

Puklavec, B., Oliveira, T., and Popovič, A. (2018). Understanding the determinants of business intelligence system adoption stages: An empirical study of SMEs. Industrial Management and Data Systems, 118(1), 236-261.

Rochet, J.-C., and Tirole, J. (2003). Platform competition in two-sided markets. Journal of the European economic association, 1(4), 990-1029.

Rogers, E. M. (1961). Bibliography on the Diffusion of Innovations. 
Saunders, B., Sim, J., Kingstone, T., Baker, S., Waterfield, J., Bartlam, B., . . J Jinks, C. (2018). Saturation in qualitative research: exploring its conceptualization and operationalization. Quality and quantity, 52(4), 1893-1907.

Scheier, M. E., and Carver, C. S. (1987). Dispositional optimism and physical well-being: The influence of generalized outcome expectancies on health. Journal of personality, 55(2), 169210.

Sheldon, K. M., and Bettencourt, B. A. (2002). Psychological need-satisfaction and subjective well-being within social groups. British Journal of Social Psychology, 41(1), 25-38.

Suls, J., Martin, R., and Wheeler, L. (2002). Social comparison: Why, with whom, and with what effect? Current directions in psychological science, 11(5), 159-163.

Walker, J. H., Saffu, K., and Mazurek, M. (2016). An empirical study of factors influencing e-commerce adoption/non-adoption in Slovakian SMEs. Journal of Internet Commerce, 15(3), 189-213.

Wang, S., Hung, K., and Huang, W.-J. (2019). Motivations for entrepreneurship in the tourism and hospitality sector: A social cognitive theory perspective. International Journal of Hospitality Management, 78, 78-88.

Weiner, B. J. (2009). A theory of organizational readiness for change. Implementation science, 4(1), 67.

Wheeler, L., Martin, R., and Suls, J. (1997). The proxy model of social comparison for self-assessment of ability. Personality and Social Psychology Review, 1(1), 54-61.

Yamin, M., and Kurt, Y. (2018). Revisiting the Uppsala internationalization model: social network theory and overcoming the liability of outsiders. International Marketing Review, 35(1), 2-17.

Zarnowitz, V., and Braun, P. (1994). Twenty-Two Years of the NBER-ASA Quarterly Economic Outlook Surveys: Aspects and Comparisons of Forecasting Performance.

Zhang, X. (2018). Frugal innovation and the digital divide: Developing an extended model of the diffusion of innovations. International Journal of Innovation Studies, 2(2), 53-64.

Zhou, P., Ang, B., and Poh, K. (2007). A mathematical programming approach to constructing composite indicators. Ecological Economics, 62(2), 291-297. 